\title{
Prediction of ESRD and long-term remission by proteinuric markers in primary focal segmental glomerulosclerosis with nephrotic syndrome: a review
}

\author{
Claudio Bazzi* \\ D’Amico Foundation for Renal Diseases Research, Milan, Italy
}

\begin{abstract}
In Primary Focal Segmental Glomerulosclerosis (FSGS) with nephrotic syndrome (NS) the most favorable prognostic factor for long-term stable renal function is remission of proteinuria in response to therapy. At present no definitive conclusions have been reached in the treatment of FSGS due to several factors: uncertainty of disease etiology, incomplete knowledge of pathogenetic mechanisms, different response to therapies and a lack of biomarkers allowing risk stratification to predict prognosis and therapy responsiveness. Recent advances in genetics and molecular biology have identified novel biomarkers with a possible pathogenetic role that may be useful for prognostic purposes. A reliable new biomarker would be able to predict remission prior to the start of treatment and outperform traditional ones, e.g. proteinuria. Novel biomarkers (podocyte-secreted angiopoietin-like 4, soluble urokinase-type plasminogen activator receptor, B7-1, urinary CD80, microRNAs) have so far not outperformed the traditional ones and added little value to a simple and cheap measurement of proteinuria. In observational studies, proteinuric biomarkers based on high molecular weight protein excretion, such as $\mathrm{IgG}$ and $\alpha 2$ - macroglobulin, showed a high predictive value for remission and progression in patients treated with steroids and cyclophosphamide. High levels of urinary apolipoprotein A1 and low levels of $\alpha 2-$ macroglobulin are suggestive of steroidsensitivity. Accordingly new treatments should take into account the predictive value of these biomarkers.
\end{abstract}

\section{Introduction}

Idiopathic Focal Segmental Glomerulosclerosis (FSGS) is a clinicopathological entity characterized by alteration of the molecular architecture of podocytes and slit diaphragms with disruption of the glomerular filtration barrier (GFB) and consequent proteinuria. The diagnosis of idiopathic FSGS is histologically characterized by focal segmental glomerulosclerosis in at least 1 glomerulus, segmental granular deposition of IgM and C3 on immunofluorescence and exclusion of secondary causes of segmental sclerosis. On the basis of various lesions associated with FSGS a classification in 5 histological types has been proposed [1] with differences in presentation, prognosis and response to therapy: the classic lesion [not otherwise specified (NOS)], perihilar, tip, cellular and collapsing lesions. Studies of animal models and familial forms have elucidated several genetic and molecular defects responsible for podocyte damage [2$4]$; increased knowledge of the molecular mechanisms of podocyte damage has not yet led to improved outcome prediction. The etiology of idiopathic FSGS is unknown. Immunological pathogenesis has been hypothesized, at least in some patients, with a clone of $\mathrm{T}$ lymphocytes secreting a permeability factor that alters GFB [5]. Recently doubts have been raised regarding the autoimmune pathogenesis of FSGS (review in 6), supported in part by the observation that certain "immunosuppressive" agents (dexamethasone and cyclosporine A) reduce proteinuria by direct stabilization of podocyte cytoskeleton $[7,8]$. The prognosis of FSGS is associated with the level of proteinuria and at present the most favorable prognostic factor for stable renal function over time and better survival is remission of proteinuria in response to corticosteroids or other treatments [9-11]. On the basis of the immunologic hypothesis, idiopathic FSGS has been treated over time with both older and relatively newer immunosuppressive agents, but treatment is still largely empirical due to variable and unpredictable responses and lack of reliable predictors for drugs responsiveness. The main goal of therapy in idiopathic FSGS with NS is to achieve remission of proteinuria to prevent development of interstitial fibrosis and progression to end stage renal disease (ESRD). To date a definitive conclusion about the treatment of the whole spectrum of patients with idiopathic FSGS and NS has not been reached for several reasons: uncertainty of disease etiology, incomplete knowledge of the pathogenetic mechanisms underlying renal damage, different response to the both older and relatively newer agents. Recent reviews of treatment $[12,13]$ have analyzed response to therapy in initial episode of NS, in patients relapsing after remission, steroid- dependent and steroid-resistant patients; some recent agents have been mainly utilized only in steroid-unresponsive patients and in mixed cohorts of children and adults, and patients with FSGS and Minimal Change Disease (MCD). To assess outcome prediction and responsiveness to treatment it would be of paramount importance the availability of reliable biomarkers able to define a risk stratification useful to more accurately predict prognosis and response to therapy.

\section{Novel biomarkers}

Recent advances in genetics and molecular biology have identified novel biomarkers that may play a pathogenetic role and could be

Correspondence to: Corres Claudio Bazzi, Fondazione D’Amico per la Ricerca sulle Malattie Renali Via Cherubini, 620100 Milano, Italy, Tel: 00393388319049 , Fax: 003902 48110814, E-mail: claudio.bazzi@alice.it

Received: October 18, 2016; Accepted: November 15, 2016; Published: November 18, 2016 
useful for non-invasive diagnosis and prognostication [14]. A recent debate published in 2015 in Nephrology, Dialysis and Transplantation on polar views concerning the usefulness of certain novel biomarkers in glomerular diseases including FSGS reached contrasting opinions: Ronco [15] summarizes the characteristics of the ideal biomarker: 1) measurement from easily available sources (blood and urine); 2) high sensitivity; 3) high specificity; 4) early detection of disease and response to treatment; 5) predictive value of prognosis and availability for stratification into categories of risk; 6) ability to provide information about the mechanism of disease. Ronco also emphasizes that the contribution of novel biomarkers such as podocyte-secreted angiopoietin-like 4 [16], soluble urokinase-type plasminogen activator receptor (suPAR) [17], B7-1 [18,19] are at present controversial as clinically useful biomarkers. De Vriese and Fervenza [20] underline that novel biomarkers such as suPAR [21], urinary CD80 [22] and microRNAs [23] have little added value to a simple and cheap measurement of proteinuria. "A more useful biomarker would be one that predicts a remission prior to the start of treatment" and "can outperform traditional ones, e.g. proteinuria". Thus, these Authors' answer to the question of whether novel biomarkers are better than conventional ones in glomerular diseases, including FSGS, is a categorical NO!

\section{Proteinuria characteristics and proteinuric biomarkers}

Proteinuria plays a key role in glomerular diseases as a marker of disease severity, as factor responsible for further renal damage both at the glomerular and tubulo- interstitial level and as an outcome predictor $[24,25]$; moreover proteinuria reduction following RAS inhibition is associated with lower progression to renal failure and improvement of kidney survival [26]. Proteinuria is primarily dependent on the GFB alterations responsible for loss of different MW proteins: high MW proteins [IgG, IgM, $\alpha 2$-macroglobulin $(\alpha 2 \mathrm{~m})]$ and medium MW proteins (albumin and transferrin) are markers of alteration of GFB; but the pathophysiology of high and medium MW proteins is different for filtration and tubular reabsorption mechanisms; the tubular reabsorption of high MW proteins is markedly lower than that of middle MW proteins, as has been recently demonstrated [27]. Low MW proteins a1- microglobulin and $\beta 2$-microglobulin and the lysosomal enzyme $\beta$-NAG are markers of tubulo-interstitial damage. Thus proteinuria measured in the final urine is a complex mixture of proteins with different MW, pathophysiological determinants and clinical significance. Notwithstanding the central role attributed to proteinuria in glomerular diseases very few studies have evaluated the usefulness of its different components as predictors of functional outcome and response to therapy. In the last few years several studies have highlighted the usefulness of the protein/creatinine/ratio and albumin/creatinine ratio for early diagnosis of clinically silent chronic nephropathies and for predicting progression, cardiovascular events and death [28-30]. Some studies evaluated whether these proteins and this type of proteinuria expression are the most powerful predictors of renal and cardio-vascular outcomes in glomerular diseases and showed that high MW proteins (IgG, IgM, a2m) [31-41] show a higher predictive value than the protein/creatinine and albumin/creatinine ratio. Moreover, the method for expressing urinary protein excretions may be relevant to its predictive value and clinical usefulness: the fractional excretion of a protein shows a higher outcome predictive value than the protein/creatinine ratio; a recently proposed method for indexing proteinuria for eGFR [42] more accurately assesses the tubular load of proteins that is one of the main mechanisms responsible for tubulo-interstitial damage and worsening renal function. Moreover, the composition of proteinuria is not stable in the course of the disease: in patients progressing to renal failure certain pathophysiological mechanisms such as reduction of nephron mass increase the permeability of GFB mainly to high MW proteins and reduces the tubular reabsorption as was demonstrated by Brenner et al. in the 5/6 nephrectomy model [43] and by Bazzi et al. in IgA Nephropathy [44]. Thus, certain properly selected proteinuric biomarkers may at present better meet the requirements suggested by De Vriese and Fervenza [19] for an optimal biomarker that "should be logistically and financially within reach, reproducible, able to predict the clinical course and response to treatment".

\section{Proteinuric biomarkers in focal segmental glomerulosclerosis}

To our knowledge only five published studies have evaluated the clinical significance of certain proteinuric biomarkers in FSGS: three in cohorts of adult patients with FSGS and NS and two in children with idiopathic NS and histologic diagnosis of FSGS or Minimal Change Disease (MCD). The first published study on the outcome predictive value of proteinuric markers in primary FSGS was a pilot study [45] followed by a subsequent study with a larger patients population; thus, only the data from the second study will be described. Bazzi et al. (46, with updated follow-up) evaluated 38 patients with idiopathic FSGS and NS who at renal biopsy had measurement of several functional (eGFR), histologic (percentage of global and segmental glomerulosclerosis, tubulo-interstitial damage score) and proteinuric markers [24 hour proteinuria $(24 \mathrm{~h} \mathrm{P})]$, urinary protein/creatinine ratio (UP/C), a2macroglobulin/creatinine ratio $(\alpha 2 \mathrm{~m} / \mathrm{C})$, Fractional Excretion of IgG (FE IgG) and a1-microglobulin (FE a 1m). Low and high risk groups for all markers were defined by cutoffs assessed by ROC analysis for progression. For the initial episode of NS the first-line therapy for all patients was steroids alone or in combination with cyclophosphamide. Twenty-three patients (61\%) went into remission as first event and 9 (24\%) progressed to ESRD. Comparing low and high risk groups, by univariate analysis remission was predicted only by FE IgG (77\% vs. $25 \%, \mathrm{p}=0.016)$ and $\alpha 2 \mathrm{~m} / \mathrm{C}(81 \%$ vs. $17 \%, \mathrm{p}=0.007)$ and ESRD at best by FE IgG ( $0 \%$ vs. $75 \%, \mathrm{p}<0.0001)$ and $\mathrm{\alpha} 2 \mathrm{~m} / \mathrm{C}(4 \%$ vs. $67 \%, \mathrm{p}<0.0001)$. By multivariate analysis FE IgG was the only independent predictor of remission and $\alpha 2 \mathrm{~m} / \mathrm{C}$ the most powerful predictor of ESRD. FE IgG and $\alpha 2 \mathrm{~m} / \mathrm{C}$ in combination increased the prediction of remission ( $83 \%$ vs. $11 \%, \mathrm{p}=0.008)$ and ESRD ( $0 \%$ vs. $89 \%, \mathrm{p}<0.0001)$ (Figure 1$)$. Twenty-one out of 23 patients with remission as first event after NS reported sustained remission after a follow up of $147 \pm 61$ months (range 60-258) obtained with steroids alone (n.5), steroids+CYP (n.13) or other treatments in 3 patients unresponsive to steroids and CYP (n.2) or steroid-dependent (n.1); [mycophenolate mofetil (n.1), pentoxifylline (n.1) and cyclosporine A (n.1), respectively. Nineteen (90\%) out of 21 patients who attained sustained remission have FE IgG below the cutoff, while all ESRD patients, unresponsive to steroids and cyclophosphamide, had FE IgG above the cutoff. In conclusion the most powerful outcome predictors were FE $\operatorname{IgG}$ and $\alpha 2 \mathrm{~m} / \mathrm{C}$, as markers for the severity of glomerular filtration barrier alterations; their predictive value, if validated in prospective studies, may be useful in clinical practice for therapeutic decisions suggesting alternative first-line treatments in high risk patients and to identify groups for controlled trials that should consist of patients with the same risk profile. Deegens and Wetzels published a study of 35 adult patients with biopsy proven primary FSGS (47); urinary markers included 24hour proteinuria, selectivity index (SI), fractional excretion of albumin, IgG, transferrin and $\beta 2$-microglobulin $(\beta 2 \mathrm{~m})$. Twenty-three patients received immunosuppressive therapy ( 9 prednisone, 14 prednisone 


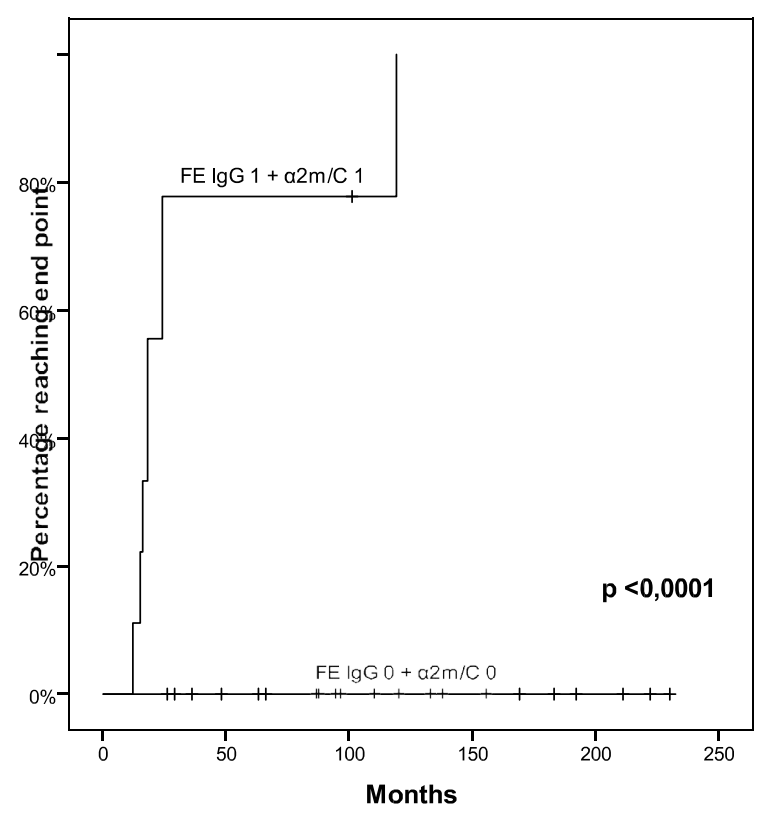

Remlsslon

$100 \%$

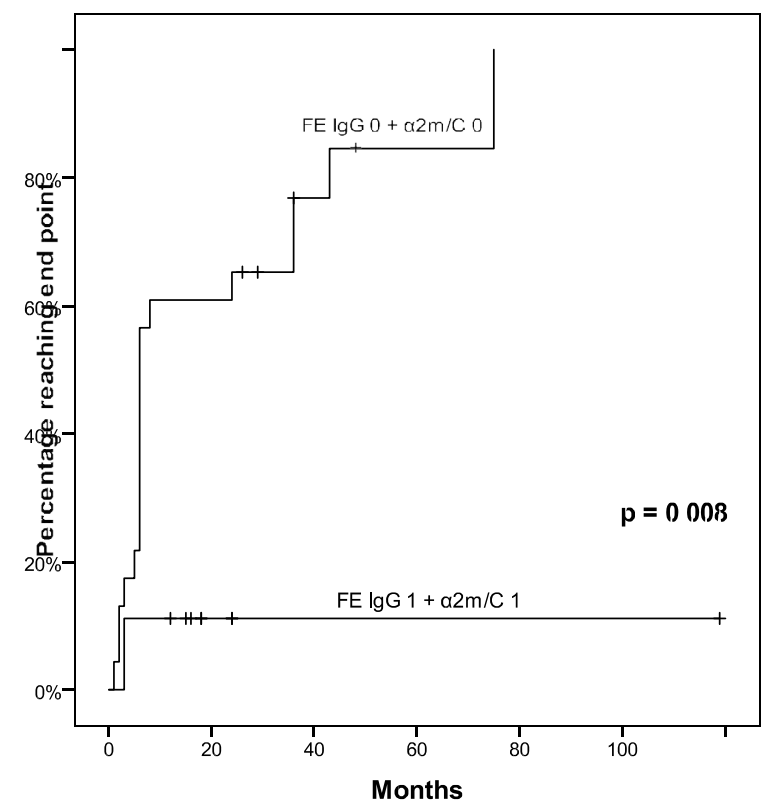

Figure 1. Probability of ESRD and remission in patients with FE IgG and $\alpha 2 \mathrm{~m} / \mathrm{C}$ both below (0) or above (1) their respective cutoffs.

and cyclophosphamide). After a median follow up of 58.3 (4.9-127.6) months, 17 patients were in remission, 6 had persistent NS and 6 had progressed to renal failure. The remission rate was similar in patients with FE IgG below or above 1.40, but more patients with FE IgG $>0.140$ received immunosuppressive therapy. The predictive value of $\mathrm{FE}$ albumin, transferrin and $\beta 2 \mathrm{~m}$ was lower. This study shows that FE $\operatorname{IgG}>0.140$ is not invariably associated with poor outcome. However the study is characterized by several limitations: $90 \%$ of patients had proteinuric markers measurements within 16 months of biopsy, 9 patients had already received a course of immunosuppressive therapy and 6 out of 9 untreated patients (67\%) developed spontaneous remission, which is a much higher percentage than the $5 \%$ spontaneous remission rate reported in the literature. Chehade et al. [48] studied 35 children with MCD and 9 with FSGS, of whom 28 in remission and 16 in relapse, and reported that urinary neutrophil-gelatinase-associated lipocalin (uNGAL), whether or not indexed to urinary creatinine, was significantly different between children with NS and healthy children $(\mathrm{p}=0.02)$, between healthy children and those with FSGS $(\mathrm{p}=0.007)$ and between children with MCD and those with FSGS ( $p=0.01$ ). uNGAL was not significantly correlated to proteinuria or GFR levels. The ROC curve analysis showed that a cutoff value of $17 \mathrm{ng} / \mathrm{mg}$ for the uNGAL/ uCreat ratio could be used to distinguish MCD from FSGS with a sensitivity of $77 \%$ and specificity of $78 \%$. Only urinary a 1 -microglobulin, indexed or not to uCreat, was significantly higher $(\mathrm{p}<0.001)$ for patients in relapse compared to those in remission. These results indicate that in this patient cohort uNGAL was a reliable biomarker for differentiating MCD from FSGS independently of proteinuria or GFR levels. The main drawback of this study was its failure to evaluate the predictive value of functional outcome and responsiveness to therapy. Suresh et al. [49] studied children with idiopathic NS due to MCD, FSGS and Membranoproliferative Glomerulonephritis (MPGN) and assessed the proteomic profile by isobaric tags for relative and absolute quantitation labeling, coupled with liquid chromatographymatrix assisted laser desorption and ionization analysis (iTRAQ/LC/ MS) in albumin- and IgG-immunodepleted samples with the aim of identifying differentially expressed urinary biomarkers in children with steroid-sensitive or steroid-resistant NS. For the discovery phase study, 27 patients were analyzed [15 steroid-sensitive NS (SSNS): 5 with first episode of NS (FENS), 5 FENS in long-term remission, 5 relapsing or steroid-dependent (FRNS/SDNS)], 12 steroid-resistant NS (SRNS) and 5 controls. For the validation phase 20 FENS, 20 FENS/SDNS, 20 SRNS and 20 age and gender matched controls were screened by enzyme-linked immunosorbent assay for the biomarkers apolipoprotein A1, $\alpha 2$-macroglobulin, orosomucoid 2, retinol binding protein 4 and leucine-rich a2-glycoprotein 1 . In the discovery phase, 26 proteins were differentially expressed, between FENS and controls: 23 upregulated and 3 downregulated. To discriminate between SSNS and SRNS 5 biomarkers were selected and measured. Significantly higher levels of apolipoprotein A1 ( $\mathrm{p}<0.001)$ differentiated FENS from SRNS (AUC 0.99 , cutoff $<0.48 \mu \mathrm{g} / \mathrm{mg}$ of urinary creatinine, $100 \%$ sensitivity and specificity $100 \%)$. A cutoff value of $<0.24 \mu \mathrm{g} / \mathrm{mg}$ of creatinine could differentiate SRNS from frequently relapsing nephrotic syndrome/ steroid dependent nephrotic syndrome [AUC 0.99, 100\% sensitivity and $100 \%$ specificity]. a2-macroglobulin could differentiate children with SRNS-FSGS from SRNS-MCD (AUC 0.84, cutoff $>3.3 \mu \mathrm{g}$ / mg creatinine); also orosomucoid 2 and Retinol Binding Protein differentiate SRNS-FSGS from SRNS-MCD. The main clinically useful conclusion to be drawn from this study was that higher levels of urinary apolipoprotein A1 is suggestive of steroid-sensitivity while lower levels identified patients with SRNS; significantly higher levels of urinary a2macroglobulin $(\mathrm{p}<0.001)$ differentiate SRNS from steroid-sensitive NS; the Authors suggest therefore that $\alpha 2 \mathrm{~m}$ is more predictive than other markers.

\section{Discussion}

At present there are no definitive conclusions regarding the therapy of idiopathic FSGS with NS; the most favorable prognostic factor for stable renal function over time is still considered to be remission of proteinuria in response to corticosteroids. Until recently, the firstline therapy for an the initial episode of NS was considered to be high dose steroids with variable treatment schedules; the most frequently 
Table 1. Clinical significance of novel biomarkers in FSGS and MCD.

\begin{tabular}{|c|c|c|}
\hline Biomarker & Author/Ref. & Clinical significance \\
\hline B7-1 & $\begin{array}{l}\text { Yu et al., } \\
2013[18]\end{array}$ & B7-1 inhibitor Abatacept induces remission of NS. \\
\hline B7-1 & $\begin{array}{l}\text { Novelli et al., } \\
2016[19]\end{array}$ & $\begin{array}{l}\text { B7-1 is not expressed in podocytes; it has no value as biomarker in } \\
\text { MCD and FSGS. }\end{array}$ \\
\hline suPAR & $\begin{array}{l}\text { Wei et al., } \\
2011[21]\end{array}$ & $\begin{array}{l}\text { suPAR is elevated in } 2 / 3 \text { of primary FSGS, but not in other glomerular diseases; high levels of suPAR before transplantation are } \\
\text { associated with increased risk of recurrence after transplantation. }\end{array}$ \\
\hline suPAR & $\begin{array}{l}\text { Li et al., } \\
2014[51]\end{array}$ & $\begin{array}{l}\text { suPAR levels are significantly higher in FSGS vs controls, MCD and } \\
\text { IMN; high levels are associated with steroid-response vs no-response. }\end{array}$ \\
\hline Apolipoprotein a-1 & $\begin{array}{l}\text { Lopez-Hellin et al., } 2013 \\
\text { [52] }\end{array}$ & Urinary Apolipoprotein a-1 found exclusively in FSGS relapsing after transplantation. \\
\hline CD80 & $\begin{array}{l}\text { Garin et al., } \\
2009[22]\end{array}$ & $\begin{array}{l}\text { Urinary soluble } \mathrm{CD} 80 \text { is significantly higher in relapsed MCD vs MCD } \\
\text { in remission. }\end{array}$ \\
\hline Angiopoietin- like-4 & $\begin{array}{l}\text { Clement et al., } \\
2011[16]\end{array}$ & Ang-1-4 is steroid-sensitive and highly upregulated in experimental model of MCD. \\
\hline NGAL & $\begin{array}{l}\text { Bennet et al., } \\
2012[53]\end{array}$ & NGAL is significantly higher in SRNS vs SSNS and controls and negatively correlated with GFR. \\
\hline NGAL & $\begin{array}{l}\text { Chelade et al., } \\
2013[48]\end{array}$ & Urinary NGAL is significantly different in NS vs controls, FSGS vs controls and FSGS vs MCD. \\
\hline microRNAs & $\begin{array}{l}\text { Zhang et al., } \\
2014 \text { [23] }\end{array}$ & $\begin{array}{l}\text { Urinary miR-196a, miR-30a-5p, and miR-490 discriminate active FSGS from FSGS in remission; urinary miR-30a-5p marginally } \\
\text { predicts steroid-responsiveness in patients with active FSGS. }\end{array}$ \\
\hline microRNAs & $\begin{array}{l}\text { Zhang et al., } \\
2015[54]\end{array}$ & $\begin{array}{l}\text { Plasma levels of miR-125b, miR-186, and miR-193-3p are increased in FSGS patients compared with healthy controls; miR-125b } \\
\text { and miR-186 levels are significantly lower in FSGS in remission than in patients with NS: plasma miR-186 level correlates with } \\
\text { proteinuria degree. }\end{array}$ \\
\hline microRNAs & Ramezani et al., 2015 [55] & FSGS and MCD patients have a unique circulating and urinary miRNA profile. \\
\hline Proteomic profile & $\begin{array}{l}\text { Wen et al., } \\
2012[56]\end{array}$ & Markedly increased levels of Haptoglobin in serum, but not in urine, are present in SRNS compared with SSNS. \\
\hline Proteomic profile & $\begin{array}{l}\text { Khurana et al., } 2006 \\
{[57]}\end{array}$ & $\begin{array}{l}\text { Five peaks distinguish SRNS; the peak at } \mathrm{m} / \mathrm{z} 11,117,4 \text { has } 95 \% \text { accuracy for classifying SRNS; this peak was identified as } \beta 2 \text { - } \\
\text { microglobulin. }\end{array}$ \\
\hline Proteomic profile & Kalantari et al., 2014 [58] & $\begin{array}{l}21 \text { urinary proteins (among them apolipoprotein A-1 and Matrix- remodelling protein 8, over- and underrepresented, respectively] had } \\
\text { the highest fold changes in steroid-sensitive vs steroid-resistant pts. }\end{array}$ \\
\hline
\end{tabular}

used schedule was oral prednisone $(1 \mathrm{mg} / \mathrm{Kg})$ for 16 weeks followed by taper or iv methylprednisolone pulses followed by oral prednisone $(0.5 \mathrm{mg} / \mathrm{d})$ for 8 weeks with subsequent taper. Steroid- resistant patients were usually defined as those who fail to go into remission at the end of 4 months of treatment. Few studies have used alternative therapies for initial episode of NS: prednisone in combination with other immunosuppressive agents (cyclophosphamide, azathioprine, cyclosporine, tacrolimus, mycophenolate mofetil) achieving variable results (review in 13). Steroid- resistant patients have been treated with the aforementioned immunosuppressive agents with variable results. Recently, Rituximab in steroid-dependent or frequently relapsing idiopathic NS in children and adults with MCD, mesangial proliferative GN and FSGS, effectively and safely prevented recurrences and reduced the need for immunosuppression [50]. One major obstacle to defining treatment guidelines is the lack of reliable biomarkers able to predict response to therapy. In the past decade genetic and molecular advances have been made in the understanding of the pathomechanisms of renal damage and novel markers for FSGS have been evaluated. At present, however, according to the opinion of influential authors these novel markers have not outperformed traditional ones, e.g. proteinuria. Very few studies in patients with FSGS assessed certain specific proteinuria components such as urinary high MW proteins (IgG, IgM and $\alpha 2$-macroglobulin) or low MW proteins ( $\alpha 1$ - microglobulin) which have displayed outcome predictive value in other glomerular diseases (IMN, IgAN, Diabetic Nephropathy, Renal Vasculitis). Two recent observational studies evaluated proteinuric components using a different biochemical approach. One study reported that Fractional Excretion of IgG in combination with a2-macroglobulin/creatinine ratio lower or higher than a cutoff assessed by ROC analysis showed a high predictive value both of remission $(83 \%$ vs. $11 \%, \mathrm{p}=0.008)$ and progression to ESRD ( $0 \% v s .89 \%, \mathrm{p}<0.0001)$ in patients treated mainly with steroids alone or in combination with cyclophosphamide. Another study on the characterization of urinary proteome reported that significantly higher levels of urinary apolipoprotein A1 were suggestive of steroid-sensitivity and lower levels were associated with steroid-resistant NS. Significantly higher levels of urinary a2macroglobulin differentiate steroid-resistant from steroid-sensitive NS. This last result confirms the observation of the previous study that showed the usefulness of a2-macroglobulin in combination with FE IgG in predicting remission and ESRD in patients with FSGS and NS. Considering that FSGS is mainly characterized by an alteration of the molecular architecture of podocytes and slit diaphragm, it would be rational to conclude that high MW protein excretion more accurately evaluates the degree of disruption of this component of GFB and that more severe disruption might be associated with progressive disease. According to these results, it appears warranted to suggest their validation in large controlled trials to evaluate the efficacy of more recent immunosuppressive agents with risk stratification based on these simple, cheap and readily available urinary biomarkers not only in steroid-resistant NS patients but also across the whole spectrum of patients with FSGS and NS.

\section{Conclusions}

Some novel biomarkers are useful to distinguish FSGS from MCD, to assess steroid-sensitivity and distinguish SRNS from SSNS and to predict relapse after transplantation; but no one of them has been evaluated for prediction of progression to ESRD. The level of urinary 
excretion of some high MW serum proteins has a high predictive value both of long-term remission and progression to ESRD.

\section{Acknowledgements}

Figure 1 and part of the introduction are derived from the paper: Bazzi $\mathrm{C}$ et al. "Urinary IgG and a2-macroglobulin Are Powerful Predictors of Outcome and Responsiveness to Steroids and Cyclophosphamide in Idiopathic Focal Segmental Glomerulosclerosis with Nephrotic Syndrome", Biomed Res Int 2013; doi.org/10.1155/2013/941831.

\section{Conflict of interest}

\section{None}

\section{References}

1. D'Agati V (2003) Pathologic classification of focal segmental glomerulosclerosis. Semin Nephrol 23: 117-134. [Crossref]

2. Löwik MM, Groenen PJ, Levtchenko EN, Monnens LA, van den Heuvel LP (2009) Molecular genetic analysis of podocyte genes in focal segmental glomerulosclerosis--a review. Eur J Pediatr 168: 1291-1304. [Crossref]

3. Gbadegesin R, Lavin P, Foreman J, Winn M (2011) Pathogenesis and therapy of focal segmental glomerulosclerosis: an update. Pediatr Nephrol 26: 1001-1015. [Crossref]

4. Rood IM, Deegens JK, Wetzels JF (2012) Genetic causes of focal segmental glomerulosclerosis: implications for clinical practice. Nephrol Dial Transplant 27: 882-890. [Crossref]

5. Shalhoub RJ (1974) Pathogenesis of lipoid nephrosis: a disorder of T-cell function. Lancet 2: 556-560. [Crossref]

6. Meyrier A (2009) Treatment of focal segmental glomerulosclerosis with immunophilin modulation: when did we stop thinking about pathogenesis. Kidney Int 76: 487-391.

7. Xing CY, Saleem MA, Coward RJ, Ni L, Witherden IR, et al. (2006) Direct effects of dexamethasone on human podocytes. Kidney Int 70: 1038-1045. [Crossref]

8. Faul C, Donnelly M, Merscher-Gomez S, Chang YH, Franz S, et al. (2008) The actin cytoskeleton of kidney podocytes is a direct target of the antiproteinuric effect of cyclosporine A. Nat Med 14: 931-938. [Crossref]

9. Chun MJ, Korbet SM, Schwartz MM, Lewis EJ (2004) Focal segmental glomerulosclerosis in nephrotic adults: presentation, prognosis, and response to therapy of the histologic variants. J Am Soc Nephrol 8: 2169-2177.

10. Meyrier A (2009) An update on the treatment options for focal segmental glomerulosclerosis. Expert Opin Pharmacother 10: 615-628. [Crossref]

11. Deegens JK, Steenbergen EJ, Wetzels JF (2008) Review on diagnosis and treatment of focal segmental glomerulosclerosis. Neth J Med 66: 3-12. [Crossref]

12. Korbet SM (2012) Treatment of primary FSGS in adults. J Am Soc Nephrol 23: 17691776. [Crossref]

13. Hogan J, Radhakrishnan J (2014) The treatment of idiopathic focal segmental glomerulosclerosis in adults. Adv Chronic Kidney Dis 21: 434-441. [Crossref]

14. Hogan J, Radhakrishnan J (2014) The treatment of idiopathic focal segmental glomerulosclerosis in adults. Adv Chronic Kidney Dis 21: 434-441. [Crossref]

15. Nafar M, Kalantari S, Samavat S, Rezaei-Tavirani M, Rutishuser D, et al. (2014) The novel diagnostic biomarkers for focal segmental glomerulosclerosis. Int $J$ Nephrol 2014: 574261. [Crossref]

16. Ronco P (2015) Moderator's view: Biomarkers in glomerular diseases--translated into patient care or lost in translation? Nephrol Dial Transplant 30: 899-902. [Crossref]

17. Estler CJ (1975) Effect of amphetamine-type psychostimulants on brain metabolism. Adv Pharmacol Chemother 13: 305-357. [Crossref]

18. Clement LC, Avila-Casado C, Matè C, et al. (2011) Podocyte-secreted angiopoietinlike-4 mediates proteinuria in gluco-corticoid-sensitive nephrotic syndrome. Nat Med 17: $117-122$.

19. Reiser J, Chapman H (2014) Soluble urokinase-type plasminogen activator receptor in FSGS: stirred but not shaken. J Am Soc Nephrol 25: 1611-1613. [Crossref]

20. Yu CC, Fornoni A, Weins A, Hakroush S, Maiguel D, et al. (2013) Abatacept in B7-1positive proteinuric kidney disease. $N$ Engl J Med 369: 2416-2423. [Crossref]
21. Novelli R, Gagliardini E, Ruggiero B, Benigni A, Remuzzi G (2016) Any value of podocyte B7-1 as a biomarker in human MCD and FSGS? Am J Physiol Renal Physiol 310: F335-341. [Crossref]

22. De Vriese AS, Fervenza FC2 (2015) Con: Biomarkers in glomerular diseases: putting the cart before the wheel? Nephrol Dial Transplant 30: 885-890. [Crossref]

23. Wei C, El Hindi S, Li J, Fornoni A, Goes N, et al. (2011) Circulating urokinase receptor as a cause of focal segmental glomerulosclerosis. Nat Med 17: 952-960. [Crossref]

24. Garin EH, Diaz LN, Mu W, Wasserfall C, Araya C, et al. (2009) Urinary CD80 excretion increases in idiopathic minimal-change disease. J Am Soc Nephrol 20: 260266. [Crossref]

25. Zhang W, Zhang C, Chen H, Li L, Tu Y1, et al. (2014) Evaluation of microRNAs miR196a, miR-30a-5P, and miR-490 as biomarkers of disease activity among patients with FSGS. Clin J Am Soc Nephrol 9: 1545-1552. [Crossref]

26. Ruggenenti P, Cravedi P, Remuzzi G (2012) Mechanisms and treatment of CKD. J Am Soc Nephrol 23: 1917-1928. [Crossref]

27. Cravedi P, Remuzzi G (2013) Pathophysiology of proteinuria and its value as outcome measure in CKD. Br J Clin Pharmacol 13: 1159-1167

28. van der Meer IM, Cravedi P, Remuzzi G (2010) The role of renin angiotensin system inhibition in kidney repair. Fibrogenesis Tissue Repair 3: 7. [Crossref]

29. Bazzi C, Rizza V, Olivieri G, Casellato D, D’Amico G (2015)Tubular reabsorption of high, middle and low molecular weight proteins according to the tubulo- interstitial damage marker N-acetyl-ß-D-glucosaminidase in glomerulonephritis. J Nephrol 28: 541-548.

30. Astor BC, Matsushita K, Gansevoort RT, et al. (2011) Lower estimated glomerular filtration rate and higher albuminuria are associated with mortality and end- stage renal disease. A collaborative meta-analysis ok kidney disease population cohorts. Kidney Int 79: 1331-1440.

31. Gansevoort RT, Matsushita K, van der Velde M, et al. (2011) Lower estimated GFR and higher albuminuria are associated with adverse kidney outcomes. A collaborative metaanalysis of general and high-risk population cohorts. Kidney Int 80: 93-104

32. Scheven L, Halbesma N, de Jong PE, de Zeeuw D, Bakker SJ, et al. (2013) Predictors of progression in albuminuria in the general population: results from the PREVEND cohort. PLoS One 8: e61119. [Crossref]

33. Bakoush O, Torffvit O, Rippe B, Tencer J (2003) Renal function in proteinuric glomerular diseases correlates to the changes in urine IgM excretion but not to the changes in the degree of albuminuria. Clin Nephrol 59: 345-352. [Crossref]

34. Bakoush O, Tencer J, Tapia J, Rippe B, Torffvit O (2002) Higher urinary IgM excretion in type 2 diabetic nephropathy compared to type 1 diabetic nephropathy. Kidney Int 61 : 203-208. [Crossref]

35. Tofik R, Aziz R, Reda A, Rippe B, Bakoush O (2011) The value of IgG-uria in predicting renal failure in idiopathic glomerular diseases. A long-term follow-up study. Scand J Clin Lab Invest 71: 123-128. [Crossref]

36. Bakoush O, Segelmark M, Torffvit O, Ohlsson S, Tencer J (2006) Urine IgM excretion predicts outcome in ANCA-associated renal vasculitis. Nephrol Dial Transplant 21 1263-1269. [Crossref]

37. Tofik R, Torffvit O, Rippe B, Bakoush O (2009) Increased urine IgM excretion predicts cardiovascular events in patients with type 1 diabetes nephropathy. BMC Med 7: 39. [Crossref]

38. Bazzi C, Rizza V, Raimondi S, Casellato D, Napodano P, et al. (2009) In crescentic IgA nephropathy, fractional excretion of IgG in combination with nephron loss is the best predictor of progression and responsiveness to immunosuppression. Clin J Am Soc Nephrol 4: 929-935. [Crossref]

39. Bazzi C, Rizza V, Paparella M, Casellato D, Napodano P, et al. (2009) Fractional urinary excretion of IgG is the most powerful predictor of renoprotection by $\mathrm{ACE}$ inhibitors in IgA nephropathy. J Nephrol 22: 387-396. [Crossref]

40. Bazzi C, Rizza V, Casellato D, Tofik R, Berg AL, et al. (2014) Fractional excretion of $\operatorname{IgG}$ in idiopathic membranous nephropathy with nephrotic syndrome: a predictive marker of risk and drug responsiveness. BMC Nephrol 15: 74. [Crossref]

41. McQuarrie EP, Shakerdi L, Jardine AG, Fox JG, Mackinnon B (2011) Fractiona excretions of albumin and IgG are the best predictors of progression in primary glomerulonephritis. Nephrol Dial Transplant 26: 1563-1569. [Crossref]

42. Branten AJW, du Duf-Vereijken PW, Klasen IS, et al. (2005) Urinary Excretion of ß2microglobulin and IgG Predict Prognosis in Idiopathic Membranous Nephropathy: A Validation Study. J Am Soc Nephrol 16: 169-174 
43. Irazabal MV, Eirin A, Lieske J, Beck LH, Sethi S, et al. (2013) Low- and highmolecular-weight urinary proteins as predictors of response to rituximab in patients with membranous nephropathy: a prospective study. Nephrol Dial Transplant 28: 137146. [Crossref]

44. Ellam TJ, El Nahas M (2011) Proteinuria thresholds are irrational: a call for proteinuria indexing. Nephron Clin Pract 118: c217-224. [Crossref]

45. Olson JL, Hostetter TH, Rennke HG, Brenner BM, Venkatachalam A (1982) Altered glomerular permselectivity and progressive sclerosis following extreme ablation of renal mass. Kidney Int 22: 112-126

46. Bazzi C, Rizza V, Casellato D, Stivali G, Rachele G, et al. (2012) Validation of some pathophysiological mechanisms of the CKD progression theory and outcome prediction in IgA nephropathy. J Nephrol 25: 810-818. [Crossref]

47. Bazzi C, Petrini C, Rizza V, et al. (2003) Fractional Excretion of IgG Predicts Renal Outcome and Response to Therapy in Primary Focal Segmental Glomerulosclerosis: A Pilot Study. Am J Kidney Dis 41: 328-335

48. Bazzi C, Rizza V, Casellato D, et al. (2013) Urinary IgG and a2-macroglobulin are powerful predictors of outcome and responsiveness to steroids and cyclophosphamide in idiopathic focal segmental glomerulosclerosis with nephrotic syndrome. Biomed Res Int.

49. Deegens JK, Wetzels JF (2007) Fractional excretion of high- and low-molecular weight proteins and outcome in primary focal segmental glomerulosclerosis. Clin Nephrol 68: 201-208. [Crossref]

50. Chehade H, Parvex P, Poncet A et al. (2013) Urinary low-molecular-weight protein excretion in pediatric idiopathic nephrotic syndrome. Pediatr Nephrol 28: 2299-2306

51. Suresh CP, Saha A, Kaur M, Kumar R, Dubey NK, et al. (2016) Differentially expressed urinary biomarkers in children with idiopathic nephrotic syndrome. Clin Exp Nephrol 20: 273-283. [Crossref]

52. Ruggenenti P, Ruggiero B, Cravedi P, Vivarelli M, Massella L, et al. (2014) Rituximab in steroid-dependent or frequently relapsing idiopathic nephrotic syndrome. $J \mathrm{Am}$ Soc Nephrol 25: 850-863. [Crossref]

53. Li F, Zheng C, Zhong Y, Zeng C, et al. (2014) Relationship between serum soluble urokinase plasminogen activator receptor level and steroid responsiveness in FSGS. Clin J Am Soc Nephrol 9: 1903-1911

54. Lopez-Hellin J, Cantarell C, Jimeno L, et al. (2013) A form of apolipoprotein a-I is found specifically in relapses of focal segmental glomerulosclerosis following transplantation. Am J Transplant 13: 493-500

55. Bennett MR, Piyaphanee N, Czech K, Mitsnefes M, Devarajan P (2012) NGAL distinguishes steroid sensitivity in idiopathic nephrotic syndrome. Pediatr Nephrol 27: 807-812. [Crossref]

56. Gabriel DA, Schaefer DJ, Roberts HR, Aronson DL, Koehler KA (1975) Prothrombin profragment-1 optical rotatory dispersion and circular dichroism. Thromb Res 7: 839846. [Crossref]

57. Zhang C, Zhang W, Chen HM, Liu C, Wu J, et al. (2015) Plasma microRNA-186 and proteinuria in focal segmental glomerulosclerosis. Am J Kidney Dis 65: 223-232. [Crossref]

58. Ramezani A, Devaney JM, Cohen S, Wing MR, Scott R, et al. (2015) Circulating and urinary microRNA profile in focal segmental glomerulosclerosis: a pilot study. Eur J Clin Invest 45: 394-404. [Crossref]

59. Wen Q, Huang LT, Luo $\mathrm{N}$ et al. (2012) Proteomic profile identifies haptoglobin as a potential serum biomarker for steroid-resistant nephrotic syndrome. Am J Nephrol 36 $105-113$

60. Khurana M, Traum AZ, Aivado M, Wells MP, Guerrero M, et al. (2006) Urine proteomic profiling of pediatric nephrotic syndrome. Pediatr Nephrol 21: 1257-1265. [Crossref]

61. Kalantari S, Nafar M, Rutishauser D, et al. (2014) Predictive urinary biomarkers for steroid-resistant and steroid-sensitive focal segmental glomerulosclerosis using high resolution mass spectrometry and multivariate statistical analysis. BMC Nephrol 15: 141.

Copyright: (C2016 Bazzi C. This is an open-access article distributed under the terms of the Creative Commons Attribution License, which permits unrestricted use, distribution, and reproduction in any medium, provided the original author and source are credited. 